Cadernos de Arquitetura e Urbanismo, v.17, n.21, 20 sem. 2010 
1. Psicóloga, mestre em Ciências Sociais, pesquisadora e extensionista do Opur - Proex/PUC Minas, professora do curso de Psicologia da PUC Minas, campus São Gabriel.

2. Graduada e especialista em Filosofia, mestre em Ciências Sociais, pesquisadora e extensionista do Opur - Proex/ PUC Minas.

3. Geógrafo, pesquisador e extensionista do Opur - Proex/PUC Minas. 


\section{O ASSOCIATIVISMO \\ CULTURAL NO BAIRRO \\ TAQUARIL - MUNICÍPIO \\ DE BELO HORIZONTE}

THE CULTURAL ASSOCIATIVING ATTHE REGION OFTAQUARIL

- CITY OF BELO HORIZONTE

Márcia Mansur Saadallah'1

Naiane Loureiro dos Santos ${ }^{2}$

Rogério Sant'Anna de Souza ${ }^{3}$

\section{Resumo}

Este trabalho configura-se como um estudo de caso do projeto de pesquisa e extensão "Monitoramento do associativismo civil em Belo Horizonte", realizado pelo Observatório de Políticas Urbanas - Proex/PUC Minas, integrante da Rede Nacional Observatório das Metrópoles. Em 2007, o curso de Psicologia da PUC Minas campus São Gabriel integrou-se a esse projeto, dando início ao trabalho no bairro Taquaril. Mediante aprofundamento de contatos chamou a atenção o número de grupos culturais na região, conduzindo o trabalho de investigação e intervenção para uma determinada área de atuação: a cultura. Com o objetivo de levantar as demandas, bem como traçar um perfil dos grupos culturais do bairro Taquaril, realizou-se um estudo de caso com 21 grupos culturais encontrados, entre setembro de 2008 e abril de 2009.

Palavras-chave: Associativismo cultural; Participação popular.

Abstract

This work is configured as a study of cases from "Monitoring of Belo Horizonte civil associativing project research", carried through by Urban Politics Observatory - Proex/PUC Minas, an integrant of Metropolitan Observatory National Net. In 2007, the course of Psychology of the PUC Minas campus São Gabriel integrated this project, giving beginning to the work in the region of Taquaril. Through by of contacts, called attention the number of cultural group in the community, leading the work of inquiry and intervention for one determined area: the culture. With objective of knowing the demands, as well as tracing a diagnosis of the cultural groups of the region of Taquaril, it happened a study of case with 21 found cultural groups, in the period between September of 2008 the April of 2009.

Key words: Cultural associativing; Popular participation. 


\section{Breve histórico do Bairro Taquaril}

4. Em http://www.favelaeissoai.com.br/ comunidades_mostra.

5. Em http://www.ibge.org.br.

Cadernos de Arquitetura e Utbanismo, v.17, n.21, 20 sem. 2010
O Bairro Taquaril localiza-se na Regional Leste do município de Belo Horizonte. Mais especificamente, entre os bairros Alto Vera Cruz, Granja de Freitas e Castanheiras, que faz divisa com o município de Sabará.

Iniciou-se o processo de ocupação com a construção do chamado Conjunto Taquaril, em 1981. A área do conjunto pertencia à Codeurb - Companhia de Desenvolvimento Urbano do Estado de Minas Gerais. Segundo a Urbel - Companhia Urbanizadora de Belo Horizonte, o Conjunto Taquaril foi dividido em 14 setores, sendo que parte do setor 12 e os setores 13 e 14 pertencem à região do Castanheiras, divisa com o município de Sabará. Sabe-se que, por volta de 1984, por intermédio do CAC-AVC Centro de Ação Comunitária Alto Vera Cruz, iniciou-se um grande movimento de luta pró-moradia no Alto Vera Cruz. Segundo informação retirada do site Favela é isso aí, ${ }^{4}$ conta-se que este movimento reuniu cerca de oito mil famílias, vindas de todas as regiões de Belo Horizonte. Foram meses de luta, em que o grupo ia a pé do Alto Vera Cruz até às portas da Prefeitura Municipal ou até o Palácio da Liberdade. Líderes comunitários contam que durante estas caminhadas ocorreram repressões dos policiais e sofrimento.

Já em 1987, a Prefeitura Municipal de Belo Horizonte, após a reivindicação do movimento dos "sem-casa", parcelou novamente a área dos sítios do terreno da extinta Codeurb em lotes de 150 $\mathrm{m}^{2}$ para atender a mais ou menos duas mil famílias. Segundo um morador antigo do bairro, Sr. Oswaldo Lopes Pedroso, as famílias precisavam construir suas casas e se mudar num prazo de apenas três meses, daí que os moradores organizaram grupos de trabalho para limpar os terrenos e construir as casas em mutirão. Nessa época, foi fundado o Centro Comunitário Pró-Construção e Desenvolvimento do Taquaril.

Após a luta por terra, veio a luta por infraestrutura urbana (energia elétrica, água, saneamento básico, criação de ruas, postos de saúde, escolas etc.). A área cresceu de forma desordenada com ocupações em áreas verdes e particulares, às margens de córregos e algumas consideradas áreas de risco geológico. O adensamento se deu pela divisão informal de lotes, que atualmente comportam duas ou mais famílias cada. As ruas do bairro receberam nomes de bairros da cidade, como Mangabeiras, Esplanada, Salgado Filho, Céu Azul, União, Gameleira, Funcionários e outros.

O conjunto foi objeto de um plano diretor próprio, devido à sua complexidade urbanística e social, elaborado pela Urbel em 1995 e atualizado em maio de 2001, que apontou a necessidade de grande número de remoções e intervenções na região.

Segundo os dados do Censo Demográfico do IBGE de 2000, ${ }^{5}$ o Bairro Taquaril possui uma população de 40.796 pessoas, com 9.057 domicílios particulares permanentes em aglomerados subnormais; $87,37 \%$ dos domicílios possuem abastecimento de água adequado, 67,29\% deles possuem escoamento sanitário adequado, 86,73\% possuem coleta de lixo adequada, 58,07\% possuem saneamento adequado, $81,14 \%$ são particulares per- 
manentes próprios, sendo que 64,97\% possuem propriedade de terreno e 16,16\% ainda não possuem; 7,91\% são domicílios alugados, 99,66\% possuem iluminação elétrica e 7,21\% não possuem banheiro.

No que tange ao percentual de famílias, por classe de renda mensal do responsável, no Bairro Taquaril, em salários mínimos (s.m.), aproximadamente $60 \%$ recebem até dois s.m. e $27 \%$ recebem de dois a cinco s.m., de acordo com dados do Censo Demográfico do IBGE 2000. A média de anos de estudos de pessoas de 25 anos e mais é de 3,9 a 5,7 anos de estudo. A taxa de alfabetização é de 81,08\%.

O próximo tópico refere-se à temática do associativismo cultural.

\section{Associativismo cultural}

6. Em http://www.abong.org.br.

Neste artigo, trabalhar-se-á com a definição de associativismo de Veiga e Rech (2002, p. 17): "Associativismo é qualquer iniciativa formal ou informal que reúne pessoas físicas ou outras sociedades jurídicas com objetivos comuns, visando a superar dificuldades e gerar benefícios para seus associados." Esse conceito é também utilizado pela Abong ${ }^{6}$ (Associação Brasileira de Organizações Não Governamentais) e possui um caráter bastante abrangente. Ao mesmo tempo, foi levada em consideração a definição de associações de acordo com a Legislação do Código Civil do Brasil, Art.53, Cap. II: "Constituem-se as associações pela união de pessoas que se organizam para fins não econômicos".

Os vínculos existentes entre as pessoas que se associam a um grupo são de diferentes naturezas, e Weber (1999) denomina "relação comunitária quando e na medida em que a atitude na ação social - no caso particular ou em média ou no tipo puro - repousa no sentimento subjetivo dos participantes de pertencer (afetiva ou tradicionalmente) ao mesmo grupo" (p. 25). Uma relação social denomina-se relação associativa "quando e na medida em que a atitude na ação social repousa num ajuste ou numa união de interesses racionalmente motivados (com referência a valores e fins)" (p. 25). Diz mais: "A relação associativa, como caso típico, pode repousar especialmente (mas não unicamente) num acordo racional, por declaração recíproca" (p. 25). Nesse sentido, existem associações onde as pessoas se unem com interesses mais pontuais, mediados por uma liderança; e existem associações de cunho mais associativo, onde há o sentimento de pertencimento a um grupo que compartilha o mesmo espaço ou território, como ocorre nas associações comunitárias ou de bairro.

Uma reflexão sobre o associativismo cultural na sociedade contemporânea constitui uma particularização dessa grande temática do associativismo. Barros (2004) aponta que atualmente as construções de novos lugares políticos para a sociedade civil passam especialmente pela experiência cultural. Dessa forma, a arte e a cultura podem ser ricos instrumentos de transformação social, potenciadoras de emancipação social e muitas vezes até econômica, abrindo novas perspectivas profissionais e de realização pessoal.

Dessa forma, a questão da cultura na contemporaneidade deve ser pensada de maneira inserida na cidade e nos atores que dela fazem parte. Nesse sentido, a cultura atualmente é parte central 
e constitutiva das práticas sociais dos moradores de determinado território. Barros (2004) diz que a cultura pode ser vista como um universo de práticas simbólicas que possibilitam a vida coletiva. Assim:

Como território de inteligibilidades e sentidos, a cultura vem se configurando como 'lugar' por excelência da construção de uma nova cidadania, concebida e praticada como algo que, para além de direitos e deveres formais, consolida encontros, identidade, participação. (BARROS, 2004, p. 4)

De acordo com Almeida (2009), a constituição das relações sociais tem íntima relação com o espaço geográfico e as diversas formas de apropriação que os sujeitos constituem nesse espaço. Nessa perspectiva, ao refletirmos sobre a produção e a manifestação cultural das periferias das grandes metrópoles, percebemos que as ruas das favelas são espaços geográficos privilegiados onde os jovens buscam alternativas de sociabilidade, de espaços de trocas e de relações de vida. Pelas ruas das favelas circulam principalmente pessoas e não carros. Assim, a rua seria o espaço do encontro e da socialização e nela estariam demarcados os vínculos sociais e parte da história de seus moradores.

Nesse sentido a arte e a cultura constituem-se como arcabouços estruturais com alta capacidade de agregação dos jovens, criando espaços para socialização e compartilhamento de suas experiências, categorias essenciais para o exercício da participação social e para a condição juvenil, uma vez que, a partir de seus encontros adquirem novas experiências e multiplicam suas vivências e experimentações. (ALMEIDA, 2009, p. 92)

Dessa forma, outra questão que nos parece pertinente é como a arte e a cultura tornam-se mecanismos privilegiados para os processos de socialização da juventude nas sociedades contemporâneas e como as ações realizadas por esses jovens estabelecem relações diferenciadas com o meio no qual estão inseridos, apresentando novas configurações, novos signos e símbolos de uso dos espaços públicos nessa comunidade.

Nos estudos das práticas culturais na cidade contemporânea, podemos dizer, que há um impacto no cotidiano da cidade no que diz respeito à formação de comunidades e públicos, e no incentivo à produção de cultura em geral. Ambos estão diretamente associados à sua mecânica de distribuição e disseminação pelo meio urbano, ou seja, à sua acessibilidade pela população. Só é possível conhecer o campo da cultura, para daí projetar a sua democratização, quando é levada em conta a conexão entre as práticas culturais, a sua espacialização e disseminação, e a mecânica de funcionamento da produção cultural.

A partir de pesquisa realizada com grupos de rap e funk de Belo Horizonte, Dayrell (2001, p. 1) afirma que "a música, a dança, o corpo e seu visual têm sido os mediadores que articulam grupos que se agregam para produzir um som, dançar, trocar ideias, postar-se diante do mundo." Percebe-se que essa perspectiva também se faz presente no universo dos grupos artístico-culturais do Taquaril, uma vez que a partir de suas ações criam espaço privilegiado para suas práticas, representações, símbolos, signos e rituais por meio dos quais os participantes constroem suas identidades. 
O próximo tópico consiste na análise dos dados coletados referentes ao perfil dos grupos culturais do Bairro Taquaril, do segundo semestre de 2008 ao primeiro semestre de 2009. Adotou-se a metodologia de entrevistas orais, previamente agendadas.

\section{Perfil dos grupos culturais do BairroTaquaril}

Os grupos identificados foram:

- Associação de Capoeira e Cultura Arte Nossa

- Grupo de Capoeira Abolição

- CDG - Comando dos Guerreiros

- CIA ArtRua

- CIA de Dança Tsunamy

- ClA Fascina

- Corações Unidos

- Kontratac do Rap

- Crime Verbal

- Davi e Luiz

- Empat Batuque

- Gamet - Grupo de Mulheres Ecumênicas do Taquaril

- HIG Stone (Alta tempestade)

- Negro B

- Oficina Rodrigo Ferreira Santos - PDC - Propriedade de Cristo cultural hip-hop

- Projeto Cultural Calanga

- Protetores do Rap

- Remanescentes

- Ctor 9

- Studio Zero

- Vozes da Periferia

Desses 20 foram categorizados como grupo cultural apenas dois: Grupo de Capoeira Abolição e Associação de Capoeira e Cultura Arte Nossa, denominados como entidade desportiva e de lazer, educacional e cultural.

A maioria das associações, o que representa 16, não possui sede própria, ou seja, dos 21 grupos cadastrados apenas cinco declararam possuir espaço próprio para desenvolver suas atividades.

A maioria dos grupos é nova, foram criados após 2000. Sete surgiram entre 2001 e 2005, 11 entre 2006 e 2009 e dois foram criados entre 1995 e 1999. Dois grupos não responderam essa questão.

Quanto ao número de componentes dos grupos, notou-se que sua composição é bastante diversificada. A maioria deles conta com quatro membros.

Em relação à faixa etária dos componentes dos grupos, a maioria possui idade entre 14 e 24 anos.

Quando perguntados sobre a faixa etária do público atendido, a opção predominante foi a faixa entre 16 e 24 anos. Percebe-se, porém, que houve uma expansão da faixa; alguns grupos assinalaram todas as opções, o que nos leva a pensar que o público que se quer atingir é qualquer pessoa que goste do trabalho que eles desenvolvem. 
Quanto ao registro dos grupos, a maioria não é registrada. Apenas dois grupos afirmaram ser registrados em cartório e quatro disseram ter outro tipo de registro, mas não falaram onde.

A maioria, representando apenas 38,10\%, dos integrantes dos grupos são trabalhadores com carteira assinada; em segundo lugar encontram-se autônomos e estudantes com 19,05\%.

Perguntados sobre o principal motivo da criação do grupo, a maioria foi criada na tentativa de envolver a comunidade na difusão e valorização da cultura; além disso, notou-se uma preocupação significativa com o combate às drogas e à violência.

Quando perguntados sobre as maiores dificuldades para a manutenção do grupo, foram apontadas em primeiro lugar a falta de mobilização e participação da comunidade e, em segundo, a falta de dinheiro e de espaço físico. Além dessas respostas foram assinaladas na opção outras: divulgação e patrocínio.

Em relação às formas de sustentação dos grupos, a principal forma consiste na troca de favores, seguida de doações e vendas. Vários deles contam com um investimento pessoal dos membros do grupo; alguns possuem uma "caixinha".

Quando perguntados sobre a periodicidade dos encontros do grupo, a maioria respondeu de uma a duas vezes por semana, o que demonstra regularidade. Normalmente eles se encontram à tarde.

Em relação às atividades desenvolvidas, praticamente todos os grupos (18) realizam apresentações culturais; 12 promovem oficinas, nove participam de eventos. Outras atividades como ensaios, criação de músicas, atividades de recreação também foram apontadas por eles.

Abaixo uma lista de atividades que os grupos julgam ser as mais importantes desenvolvidas por eles.

- Atividade com a Apae e Sociedade Pestalozzi na comunidade

- Apresentação em escolas, na UFMG, no Centro Cultural e no Bairro Vera Cruz

- Feira de artesanato, Arte do morro e Seminário da Juventude

- Cursos, apresentações em São Paulo e Rio de Janeiro

- Espetáculo de dança afro; festa de aniversário do grupo

- Grafite, aulas de rádio

- Evento Metamorfose (só para mulheres), em Salvador (Trio elétrico); Evento Bom Som no Centro de BH

- Eventos em danceterias e no próprio bairro

- Kizumba, Liga dos MCs, Arena da Cultura

- Música, computação e artesanato

- Apresentações na praça, atividades no centro comunitário, oficinas de rádio

- Oficinas de rap e de grafite

- Participação na Arena da Cultura e em shows

- Eventos: Vem Capoeirar, Circuito de Regional de Capoeira, Capoeira Regional Leste, Granja sem fome

- Visita ao Centro de internações de viciados, penitenciária, Hospital HIV, e a doentes em estágio terminal

- Semana do meio ambiente Simpro 
- Primeira intervenção de grafite feminino

- Mutirões de grafite (MUC)

Quanto à participação/mobilização social e política, questionouse se os membros do grupo já tinham participado de abaixoassinado; 11 deles disseram que sim; manifestação, oito deles responderam que sim; greve, nenhum deles; boicote político, quatro deles. Tais atividades são desenvolvidas na maioria das vezes nos finais de semana.

Quanto à infraestrutura dos grupos, a maioria (16) afirma ter acesso à internet, telefone (13) e Rádio Comunitária (nove). Entretanto, a Rádio Comunitária foi fechada no período de realização das entrevistas (fevereiro de 2009).

Quando perguntados se existe local de lazer no bairro, a maioria, 14 representantes de grupos culturais, disse que sim, e sete disseram que não. O local de lazer mais citado no bairro foi, em primeiro lugar, a Praça Che Guevara, em segundo lugar a Escola Municipal do bairro. Ao questionar se os grupos utilizam esses espaços, a maioria (13) disse que não, contra oito, que responderam que sim. Perguntados sobre os motivos de não utilizarem esses espaços, eles não souberam explicar, alguns disseram ser burocrático, outros que é um espaço mal equipado para apresentações culturais e que, portanto, preferem outros locais.

Em relação aos objetivos pretendidos pelos grupos, a maioria vinculou suas respostas à questão da conscientização, socialização e resgate cultural. Três grupos têm como objetivo a geração de renda e o reconhecimento do talento dos membros do grupo. Um afirmou como objetivo principal o afastamento das pessoas das drogas.

A tabela abaixo aponta as dificuldades e facilidades encontradas pelos grupos. De acordo com as respostas coletadas, a maior dificuldade encontrada é a falta de recursos financeiros, em segundo lugar a falta de apoio e patrocínio. Em relação às facilidades, a força de vontade, seguida do dom artístico, foram as mais ressaltadas.

Tabela 1

Dificuldades e facilidades

\begin{tabular}{l|l|l|l}
\hline & $\mathrm{N}^{\circ}$ & & $\mathrm{N}^{\circ}$ \\
\hline Aceitação & 4 & Força de vontade & 5 \\
\hline Falta de oportunidade & 4 & Apoio & 2 \\
\hline Apoio/patrocínio & 8 & Participação & 2 \\
\hline Espaço físico & 4 & Satisfação & 1 \\
\hline Equipamento & 3 & Mobilidade & 1 \\
\hline Recurso financeiro & 11 & Dom artístico & 3 \\
\hline Vontade/mobilização/participação & 4 & Criatividade & 1 \\
\hline Transporte & 4 & Parcerias & 1 \\
\hline Alimentação & 1 & Diálogo com o público & 1 \\
\hline Falta de policiamento & 1 & Oferta de oficina & 1 \\
\hline Organização/estruturação do grupo & 1 & Equipamento & 1 \\
\hline Divulgação & 3 & Rádio Taquaril & 1 \\
\hline Tempo & 2 & Articulação política & 1 \\
\hline Livre acesso de transitar no bairro & 1 & & \\
\hline
\end{tabular}


Quanto à natureza das demandas, as mais apontadas foram de cunho financeiro (18) e disponibilidade de tempo (18), seguidas de mobilização/participação popular (16) e vontade política (16).

Ao indagar se o grupo teria outras atividades a realizar, a maioria (19) afirmou ter potencialidades. No geral, chamaram a atenção para ações culturais, políticas, sociais e comunitárias. Essas potencialidades, de acordo com as respostas coletadas, consistem em:

- Cantar, dançar e tocar;

- Palestras de conscientização à população dos benefícios que o jovem pode fazer;

- Criação de outras oficinas, campanhas de conscientização comunitária e espetáculos de dança;

- Curso de capacitação gerando certificado que dê referência para a pessoa se inserir no mercado de trabalho;

- Penteado afro;

- Oficinas;

- Recreação;

- Teatro da capoeira como: Maculelê, dança afro, puxada de rede;

- Trabalhar com dependentes químicos;

- Evento voltado para a cultura do rock;

- Encontros de poesia.

Para realizá-las seria necessário, segundo os entrevistados, em primeiro lugar infraestrutura (espaço físico, instrumentos, figurino etc.), em segundo, apoio político e da comunidade, em terceiro, oportunidade e recursos financeiros.

Quanto à comunicação entre os grupos, 19 disseram que existe. Apenas dois grupos discordaram. Perguntou-se de que forma essa relação acontece, oito responderam que acontece em apresentações, eventos, encontros culturais no Taquaril. Alguns grupos disseram que essa comunicação/relação é limitada por diversos fatores, mas não disseram quais. Ainda sobre essa questão, perguntou-se sobre a existência de algum tipo de organização entre os grupos, a maioria (15) disse que sim, contra seis, que disseram que não. Dos que responderam que há, cinco falaram que essa organização acontece em reuniões, quatro disseram que acontece em eventos, um em apresentação cultural, um para divulgação e um grupo mencionou a Aliança Cultural do Taquaril, mas ressaltou que ela se encontrava desativada no momento. Apenas um utilizou a palavra "parceria" e um grupo disse que existe respeito entre os grupos.

Quando perguntados se o grupo já participou de alguma capacitação ou programa de formação, a maioria (12) disse que não, contra nove grupos que afirmaram que já participaram de atividades como: Arena da Cultura, Aula de rádio, Capacitação Gerrar e Políticas Públicas, Capacitação Oficineiros Fica Vivo, Gerenciar seu próprio negócio, Centro Mineiro de Referência e Resíduos, Oficina de Arte Favela, PPJ Direitos Humanos, Seminário de oficineiros, Stop Droga, Congresso Nacional Antidrogas, Congresso Intermunicipal, Trabalho em equipe e Oficinas Culturais.

Quando perguntados quais eram os principais fatores incentivadores para as pessoas participarem de atividades culturais, a opção mais respondida foi informar-se (19), em seguida diversão e namorar (18), em terceiro lugar divulgação (propaganda) (17). 
$\mathrm{Na}$ opinião dos grupos entrevistados a atividade cultural pode produzir benefícios para a comunidade, principalmente afastando as pessoas do caminho das drogas e da criminalidade e incentivando-as culturalmente a participarem da comunidade na qual vivem. Os depoimentos dessa questão encontram-se abaixo:

A cultura de certo modo tende a mostrar vários outros caminhos. Nas comunidades onde a criminalidade é alta, são de extrema importância outras atividades para os jovens. E a cultura é uma dessas atividades onde se trabaIha o corpo e a mente.

Afastando pessoas de coisas ruins, aumentando conhecimento, proporcionando expectativas de vida.

Ajuda os meninos a saírem das ruas, do mundo das drogas.

As pessoas são incentivadas à cultura.

Dar reconhecimento às pessoas que participam; mostrar o que há de bom na comunidade.

Divulgando e mostrando o trabalho que os grupos realizam. É um jeito de mostrar a comunidade.

Formação do cidadão; visibilidade melhor para a comunidade.

Incentivar através dos eventos culturais a comunidade, pois abrem, de certa forma, a mente das pessoas; reconhecer e acessar seus direitos, lazer, segurança, deveres, nos espaços e nas comunidades.

Mostrando potencial que a favela tem e que existe o lado bom das coisas.

Mostrar o que de há de bom na associação, retirando os adolescentes das ruas, pois acreditamos que enquanto estão treinando estão afastados dos riscos sociais.

Na construção de conhecimento, no convívio social e na construção identitária.

Os benefícios através de atividades que fossem aproveitadas de forma educativa, social e comunitária.

Pode mostrar uma comunidade em que não só os jovens, mas todo mundo pode mudar o bairro.

Redução de criminalidade; reduzir o envolvimento dos jovens com drogas. Ocupação dos horários vagos dos jovens.

Ser multiplicador do trabalho desenvolvido, atingindo os objetivos.

Tirar pessoas da rua; oportunidade.

Uma das melhores coisas que pode ajudar é produzir meIhor.

Conscientização; como utilizar o espaço para interação.

Divulgação da comunidade.

Divulgação para a comunidade. 
Com base no diagnóstico realizado e em documentos levantados citados nas referências bibliográficas, notou-se que o Taquaril apresenta um alto potencial cultural. Segundo Souza e Gerson (2008), autores do projeto Mapeamento dos recursos comunitários para a juventude Taquaril, financiado pela $\mathrm{PBH}$, em 2008, há na comunidade muitas habilidades artísticas como: música, canto, pintura, desenho, dança, artesanato, ilusionismo, grafite, entre outras.

Observou-se no Taquaril uma forte cultura voltada para a formação de grupos de rap, hip hop, danças e capoeira. Os jovens vêem na cultura um meio de interagirem, de manifestarem sua forma de pensar, de ver o mundo e a realidade que os cerca. O número de grupos é considerável em relação ao tamanho da população do Taquaril. Estima-se que esse número seja ainda maior, por volta de 30 .

Porém, a articulação entre os grupos merece reflexão. Na avaliação feita pela comunidade, os grupos se conhecem, respeitam um ao outro, mas não estabelecem uma integração, uma parceria no desenvolvimento de suas atividades. Se esta existisse, poderia fortalecer ainda mais a cultura no bairro, além de somar forças para conquistas relacionadas aos itens que os próprios grupos apontaram no questionário: mobilização/participação da comunidade, aceitação, apoio político/patrocínio, entre muitos outros.

Contudo, os grupos no Taquaril já estiveram bem mais articulados. Moradores da região afirmam que há um tempo os grupos eram articulados e existia um trabalho de parceria entre eles que se perdeu a partir do momento em que os grupos começaram a se preocupar mais com as apresentações culturais do que com o desenvolvimento do grupo. Nesse sentido, seria interessante um resgate da aliança cultural do Taquaril mediante encontros, seminários, oficinas na comunidade, nos quais os grupos possam não só mostrar seu trabalho, mas também trocar experiências e discutir questões comuns da comunidade do Taquaril, como, por exemplo, o fechamento da rádio comunitária em fevereiro de 2009. Essa intervenção seria realizada tendo em vista as várias formas e modelos de manifestações associativas do bairro, e em alguns momentos focada nos grupos ligados às manifestações artísticas e culturais da comunidade.

A cultura popular é o resultado de uma interação contínua do homem com o ambiente onde vive. A cultura está presente em diversas áreas do conhecimento: crenças, artes, moral, linguagem, ideias, hábitos, tradições, costumes, artesanato, folclore etc. Uma manifestação cultural pode retratar as transformações ocorridas em um meio social. Quando uma pessoa ou um grupo tenta exteriorizar, verbalizar, desenhar, sob a forma de uma música, de uma poesia, de um desenho, de uma dança etc., existe ali uma tentativa de se estabelecer um contato, uma aproximação com os segmentos da sociedade, sejam eles políticos, sociais, comunitários ou até mesmo familiares. Portanto, a cultura popular, produto das relações sociais e das diversas maneiras de se pensar a realidade, pode se tornar um direcionamento para uma comunidade. 


\section{Referências}

ALMEIDA, Miguel Renato. Cultura como mediação: configurações territoriais e juventude na favela. In: BARROS, José Márcio; ALENCAR, R.; MELO, T. (Org.). As mediações da cultura: arte, processo e cidadania. Belo Horizonte: Editora PUC Minas, 2009.

Associação Brasileira de Organizações Não-governamentais - Abong, São Paulo. Disponível em: http://www.abong.org.br. Acesso em: 5 ago. 2009.

BARROS, Jose Márcio. Prefácio. In: LIBÂNIO, Clarice de Assis. Guia cultural das vilas e favelas de Belo Horizonte. Belo Horizonte: Habitus, 2004. p. 4.

BARROS, José Márcio; ALENCAR, R.; MELO, T. (Org.). As mediações da cultura: arte, processo e cidadania. Belo Horizonte: Editora PUC Minas, 2009.

CLAVAL, Paul. A geografia cultural. 3. ed. Florianópolis: UFSC, 2007.

Código Civil do Brasil. Brasília: Presidência da República Federativa do Brasil. Disponível em: http://www.planalto.gov.br. Acesso em: 10 jun. 2009.

Comunidades. Favela é Isso aí. Belo Horizonte: Comunidades. Disponível em: http://www.favelaeissoai.com.br/comunidades_ mostra. Acesso em: 16 abr. 2009.

COURA, Claudineia Pereira. Trajetórias e representações sociais dos jovens urbanos. Observatório das Metrópoles, Artigos semanais, abr. 2009. Disponível em: <http://web.observatoriodasmetropoles.net/index.php?option=com_content\&view=article\& id=932:juventude-e-segregacao-urbana\&catid=34:artigos\&ltemi $d=138$ \&lang=pt $>$. Acesso em: 15 abr. 2009.

DAYRELL, Juarez. A música entra em cena: o rap e o funk na socialização da juventude em Belo Horizonte. 2001. Tese (Doutorado) - Faculdade de Educação, Universidade de São Paulo, São Paulo.

GOHN, Maria da Glória (Org.). Movimentos sociais no início do século XXI: antigos e novos atores sociais. Petrópolis: Vozes, 2003.

Instituto Brasileiro de Geografia e Estatística. Rio de Janeiro: IBGE. Disponível em: http://www.ibge.org.br. Acesso em: 16 abr. 2009.

LIBÂNIO, Clarice de Assis. Guia cultural das vilas e favelas de Belo Horizonte. Belo Horizonte: Habitus, 2004.

Observatório de Políticas Urbanas - Proex/PUC Minas. Relatório da pesquisa levantamento de demandas no bairro Taquaril. $2^{\circ}$ semestre de 2008/1 semestre de 2009, p. 23.

Observatório de Políticas Urbanas da Pró-reitoria de Extensão da PUC Minas. Belo Horizonte: PUC Minas. Disponível em: http://www.proex.pucminas.br/observatorio. Acesso em: 16 abr. 2009.

Prefeitura Municipal de Belo Horizonte. Belo Horizonte: PBH. Disponível em: http://www.pbh.gov.br. Acesso em: 16 abr. 2009.

Rede Nacional Observatório das Metrópoles. Rio de Janeiro: IPPUR-RJ. Disponível em: http://www.observatoriodasmetropo- 
les.net. Acesso em: 10 jun. 2009.

SANTOS JUNIOR, Orlando Alves. Cidade, democracia e justiça social. Rio de Janeiro: Fase, 2004.

SOUZA, Bruno Cesar de; GERSON, Daniel. Projeto de mapeamento dos recursos comunitários para a juventude Taquaril. Belo Horizonte: PBH, 2008.

VEIGA, Sandra Mayrink; RECH, Daniel. Associações: como constituir sociedades civis sem fins lucrativos. Rio de Janeiro: Fase, 2002.

WEBER, Max. Economia e sociedade. 4. ed. Brasília: Editora UnB; São Paulo: Imprensa Oficial, 1999. v. 1.

\section{Endereços para correspondência}

Márcia Mansur Saadallah

mansursadala@yahoo.com.br

Naiane Loureiro dos Santos

naiane@pucminas.br

Rogério Sant'Anna de Souza

rogsantanna@gmail.com 
